\section{ALAN TURING: PERSON OF THE XXth CENTURY? ${ }^{1}$}

\author{
José M. Sánchez Ron \\ Universidad Autónoma de Madrid \\ Real Academia Española \\ jmsron@rae.es
}

Citation/Cómo citar este artículo: Sánchez Ron, J. M. (2013). "Alan Turing: Person of the XXth Century?". Arbor, 189 (764): a085. doi: http://dx.doi.org/10.3989/arbor.2013.764n6008

Received: 10 July 2013. Accepted: 15 September 2013.

ABSTRACT: In December 1999, "Time" magazine chose Albert Einstein as "Person of the Century." This was undoubtedly a reasonable choice, but as I will argue in this article, there are also good reasons for contending that Turing might have received this honor. One such reason I consider here is his purely scientific work, which stems from the greatest mathematical tradition, and how it affected the development of mathematics itself and was finally instrumental in shaping a new technological world. This is true both as regards the computation and treatment of information as well as the establishment of new forms of social relations. In relation to the foregoing, we have Turing's contributions to the deciphering of secret codes during the Second World War, which in a somewhat metaphorical sense may be regarded as a new tool for undermining personal privacy, that civil right whose denial finally ruined his life.

KEYWORDS: mathematics; logic; cryptography; scientific computation; artificial intelligence.

\section{ALAN TURING: ¿PERSONAJE DEL SIGLOXX?}

Copyright: (c) 2013 CSIC. This is an open-access article distributed under the terms of the Creative Commons Attribution-Non Commercial (by-nc) Spain 3.0 License.
RESUMEN: En diciembre de 1999, la revista Time eligió a Albert Einstein "The Person of the Century". Fue, no cabe duda, una elección razonable, pero, como se argumenta en este artículo, existen también buenos argumentos para sostener que Turing podría haber recibido tal honor. En apoyo de semejante tesis están sus trabajos puramente científicos, que se esbozan aquí, trabajos que entroncan con la mejor tradición matemática, y cómo afectaron al desarrollo matemático, siendo finalmente instrumentales en la configuración de un nuevo mundo tecnológico, tanto en lo que al cálculo y manejo de información se refiere, como en lo relativo al establecimiento de nuevas formas de relaciones sociales. Relacionadas con lo anterior, se encuentran las aportaciones que hizo durante la Segunda Guerra Mundial al desciframiento de códigos secretos, que, en cierto sentido, metafórico, se pueden considerar como una nueva herramienta para socavar la privacidad, ese derecho civil cuya negación arruinó su propia vida.

PALABRAS CLAVE: matemáticas; lógica; criptografía; inteligencia artificial; informática. 


\section{INTRODUCTION}

The December 31st, 1999 issue of Time, the weekly American journal, had on its cover a photograph of Albert Einstein under the heading of "Person of the Century." What were the criteria that guided Time in its choice? This is what the editors of Time had to say on the matter:

"So how can we go about choosing the Person of the Century, the one who, for better or worse, personified our times and will be recorded by history as having the most lasting significance?

Let's begin by noting what our century will be remembered for. Out of the fog of proximity, three great themes emerge:

- The grand struggle between totalitarianism and democracy.

- The ability of courageous individuals to resist authority in order to secure their civil rights.

- The explosion of scientific and technical knowledge that unveiled the mysteries of the universe and helped secure the triumph of freedom by unleashing the power of free minds and free markets."

Confronted with these grand themes, Time chose three finalists: Franklin D. Roosevelt, Mohandas Gandhi and Albert Einstein. I will have more to say later about Roosevelt and Gandhi, but let me begin with Einstein.

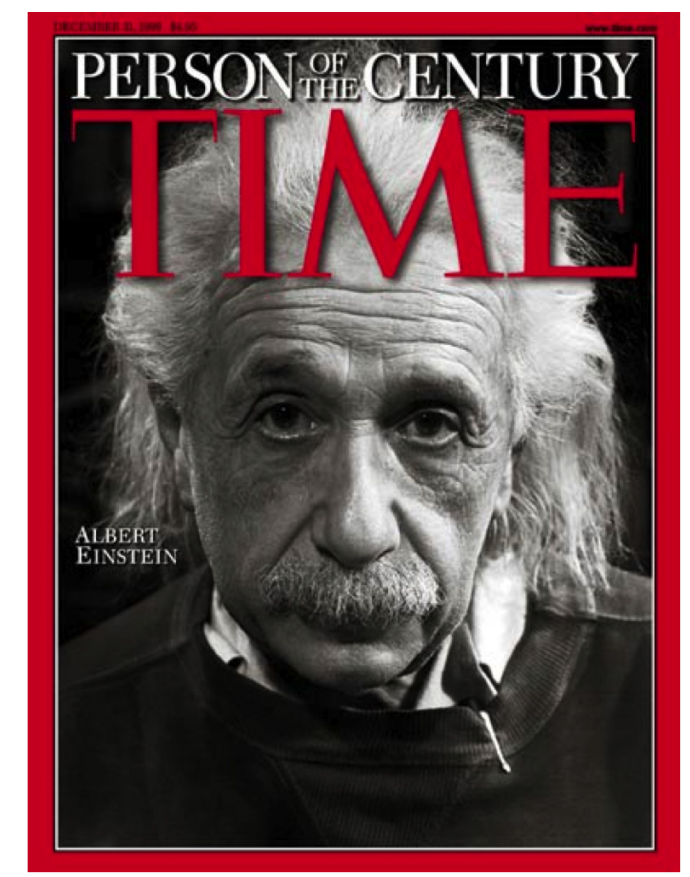

\section{THE CENTURY OF SCIENCE AND TECHNOLOGY}

The opening article, signed by Walter Isaacson (1999), reads as follows: "In a century that will be remembered foremost for its science and technology - in particular for our ability to understand and then harness the forces of the atom and the universe - one person stands out as both the greatest mind and paramount icon of our age: the kindly, absentminded professor whose wild halo of hair, piercing eyes, engaging humanity and extraordinary brilliance made his face a symbol and his name a synonym for genius: Albert Einstein."

"A century that will be remembered foremost for its science and technology", wrote Isaacson, and indeed I agree with him. Of course, Einstein was a good choice. However, I will argue that another plausible choice, though certainly not so popular, would have been Alan Turing (1912-1954).

As arguments in favor of Einstein, Time mentioned his contributions to quantum physics, the two theories of relativity (the special and the general) and the relativistic cosmology that led to a new understanding of the Universe. They were indeed impressive contributions having far-reaching consequences, not only scientific and technological but also philosophical and cultural, but now, living as we do in a new century and possessing a broader perspective of the scientific and technological innovations of the XXth century that exerted the greatest influence on the future, were they really those associated with Einstein's name?

It is difficult to answer to this question. The deep meaning of the special and general theories of relativity, with all they tell us about such basic concepts as space and time, makes it hard to deny their fundamental importance when compared with practically any other scientific theory. In a similar way, although not in the same sense as relativity to space and time, we might also speak about quantum physics. Actually, as far as its social (political and economic) consequences are concerned, quantum physics has proved to be far more important than relativity (we only have to think about the transistor), although in this case Einstein was simply one more name alongside others, especially Max Planck, Niels Bohr, Werner Heisenberg and Erwin Schrödinger.

If we look around, a possible answer to the question of what the most important innovation for our XXIst society is might be found in all the gadgets and control systems which make Globalization possible - what we 
call the Information Era - and it is here where Alan Turing's name stands out very prominently. Of course, I do not mean to say that his is the only name to consider, but his position is reinforced if we take into account the number and diversity of his contributions - to logic, mathematics, cryptanalysis, philosophy, and formatively to the areas later known as computer science, cognitive science, artificial intelligence and artificial life.

Actually, Time recognized the importance of Globalization: "Even more central to this globalization" wrote Isaacson after referring to Henry Ford and the Wright brothers, "were the electronic technologies that revolutionized the distribution of information, ideas and entertainment." And at this point he mentioned Turning, but only very briefly: "In the 1930s Alan Turing first described the computer - a machine that could perform logical functions based on whatever instructions were fed to it - and then proceeded to help build one in the early 1940s that cracked the German wartime codes. His concepts were refined by other computer pioneers: John von Neumann, John Atanasoff, J. Presper Eckert and John Mauchly."

\section{FOUNDATIONS OF MATHEMATICS}

To mention Turing only in connection with computers is a great misunderstanding. He belongs to a mathematical movement or tradition that during the second half of the XIXth century dramatically changed the very idea of mathematics. A more detailed presentation however should also necessarily include Galois, who was highly influential in converting mathematics into the study of structures; Lobachevskii, Bolyai and Riemann with their non-Euclidean geometries; Felix Klein with his Erlangen Program in which he put forward the idea that there are as many geometries as transformation groups, and George Cantor, with his theory of transfinite numbers, which gave a new dimension to set theory. As forerunners to the mathematical tradition to which Turing belonged, I would also mention George Boole (1815-1864) and David Hilbert (1862-1943).

In the opening lines of An Investigation on the Laws of Thought (1854), Boole wrote:

"The design of the following treatise is to investigate the fundamental laws of those operations of the mind by which reasoning is performed; to give expression to them in the symbolic language of a Calculus, and upon this foundation to establish the science of Logic and construct its method; to make that method itself the basis of a general method for the application of the mathematical doctrine of Probabilities; and, finally, to collect from the various elements of truth brought to view in the course of these inquires some probable intimations concerning the nature and constitution of the human mind."

And further later on in the book, almost at the end of chapter II:

"Let us conceive [...] of an Algebra in with symbols $x, y$, $z$, etc. admit indifferently of 0 and 1 , and of these values alone. The laws, the axioms, and the processes, of such an Algebra will be identical in their whole extent with the laws, the axioms, and the processes of an Algebra of Logic."

Boole of course was speaking about what we now know as "digitalization."

As to Hilbert, in 1899 he published a book, Grundlagen der Geometrie (Foundations of Geometry), in which in a sense he went further than Lobachevskii, Bolyai and Riemann by axiomatizing geometry completely, showing the purely formal character that algebra and analysis had already achieved. Although we can say that such a work shed light on the foundations of mathematics, it is not of the sort of approach to which I wish to refer now. However, Hilbert also contributed to the foundations of mathematics understood in that sense, most importantly in the lecture he delivered at the eighth International Congress of Mathematicians held in Bologna in 1928 (it was the first time since the First World War that a German delegation had participated in these Congresses, with a group of 67 mathematicians headed by Hilbert).

In the paper he read in Bologna, Hilbert addressed a very important problem, the so-called Entscheidungsproblem, or "decision problem", with the aim of showing if an algorithm existed for deciding if a mathematical proposition is a logical consequence of others, a subject that he had already considered in his famous 1900 Paris lecture, as part of problem number 2 ("The compatibility of the arithmetic axioms") (Hilbert, 1902)2. It is interesting to quote some of what Hilbert said in Bologna (Hilbert, 1929, 1930):

"In a series of presentations in the course of the last years I have [...] embarked upon a new way of dealing with fundamental questions. With this new foundation of mathematics, which one can conveniently call proof theory, I believe the fundamental questions in mathematics are finally eliminated, by making every mathematical statement a concretely demonstrable and strictly derivable formula [...]

In mathematics there is no ignorabimus, rather we are always able to answer meaningful questions, and it is 
established, as Aristotle perhaps anticipated, that our reason involves no mysterious arts of any kind: rather it proceeds according to formulatable rules that are completely definite - and are as well the guarantee of the absolute objectivity of its judgments."

Of course, Hilbert could not imagine that only three years later, in 1931, the Austrian logician Kurt Gödel (1906-1978) would demonstrate that indeed there is ignorabimus in mathematics; that mathematical statements exist that are incomplete and undecidable; more specifically, that the formal system of arithmetic set out by Alfred North Whitehead and Bertrand Russell in their seminal Principia Mathematica (1910, 1912,1913 ) is, if consistent, incomplete; that is, if the system, the basic mathematical system, is consistent, there are true statements of arithmetic that are not provable in the system (Gödel, 1931). Gödel's result ranks among the most important results in the entire history of science, with implications that go far beyond mathematics, affecting philosophy deeply, much as Einstein's conception of space and time did.

In 1936, and partially using Gödel's results, the American logician Alonzo Church (1903-1995) tackled Hilbert's Entscheidungsproblem and arrived at the conclusion - in the last sentence of the paper - that "if the system of Principia Mathematica be $\omega$-consistent, its Entscheidungsproblem is unsolvable" (Church, 1936a; Church, 1936b; Church, 1936c). Church's results had already been published when in April Turing presented a draft of a paper in which he also tackled Hilbert's Entscheidungsproblem, to one of his teachers at Cambridge (Turing had joined Cambridge University in October 1931), the topologist Maxwell H. A. Newman (1897-1984) a lecturer in Mathematics there since $1927^{3}$. In May, while Newman was still studying Turing's paper, he received an offprint of Church's article. However, he believed Turing's approach to be different and in some respects more attractive and powerful than Church's, and told his young disciple so. Somewhat relieved, Turing published his article ${ }^{4}$. It was his famous "On computable numbers, with an application to the Entscheidungsproblem" (1937) .

This now famous article began as follows: "The 'computable' numbers may be described briefly as the real numbers whose expressions as a decimal are calculable by finite means. Although the subject of this paper is ostensibly computable numbers. it is almost equally easy to define and investigate computable functions of an integral variable or a real or computable variable, computable predicates, and so forth. The fundamental problems involved are, however, the same in each case, and I have chosen the computable numbers for explicit treatment as involving the least cumbrous technique". It soon went on to point out:

"Although the class of computable numbers is so great, and in many ways similar to the class of real numbers, it is nevertheless enumerable. In $\S 81$ examine certain arguments which would seem to prove the contrary. By the correct application of one of these arguments, conclusions are reached which are superficially similar to those of Gödel. These results have valuable applications. In particular, it is shown (§11) that the Hilbertian Entscheidungsproblem can have no solution." Conscious of Church's work, Turing immediately added: "In a recent paper Alonzo Church has introduced an idea of 'effective calculability', which is equivalent to my 'computability', but is very differently defined. Church also reaches similar conclusions about the Entscheidungsproblem. The proof of equivalence between 'computability' and 'effective calculability' is outlined in an appendix to the present paper."

Since Church preceded Turing in the demonstration of Hilbert's Entscheidungsproblem, one might wonder why we now especially remember Turing and not Church. The answer to this relevant question is that Church's procedure, the so called "lambda calculus", was more involved and did not offer the possibilities that Turing's did. Gödel, for example, used to refer to Turing and not to Church. Thus, as regards the question of whether to include one or two of the papers that Gödel had published in 1934, together with his 1931 classic, as appendices to the book Gödel's Proof that Ernest Nagel (1901-1985) and James R. Newman (1907-1966) had written (it was finally published by New York University Press in 1958, without Gödel's articles), Gödel wrote Nagel, from Princeton, on March 14, 1957 (Gödel, 2003): "Considerable advances have been made in these questions since 1934. Not to mention other things, it was only by Turing's work that it became completely clear that my proof is applicable to every formal system containing arithmetic. I think the reader has the right to be informed about the present state of affairs."

The following year, in an article published in Dialectica, Gödel commented again on Turing's paper (Gödel, 1958):

"As is well-known, A. M. Turing, using the notion of a computing machine, gave a definition of the computable function of the first order. But, had this notion not already been intelligible, the question of whether Turing's definition is adequate would be meaningless $[\ldots]$ 
It is well-known that A. M. Turing has given an elaborate definition of the concept of a mechanically computable function of natural numbers. This definition most certainly was not superfluous. However, if the term 'mechanically computable' had not had a clear, although unanalyzed, meaning before, the question as to whether Turing's definition is adequate would be meaningless, while it undoubtedly has an affirmative answer."

Of course, it is clear why Gödel was interested in Turing's works: Turing's contribution gave a more general definition of formal system, something that allowed Gödel to refine later his theorem showing that incompleteness could "be proved rigorously for every consistent formal system containing a certain amount of finitary number theory." (Gödel, 1974) .

In the same year that "On computable numbers" appeared, and following the suggestion by Newman, Turing left his fellowship at King's College, Cambridge (he had been elected fellow of King's in 1935), for the United States and Princeton University, where in addition to Church he found luminaries such as Albert Einstein, John von Neumann and Herman Weyl, the latter three at the Institute for Advanced Studies, as well as Solomon Lefschetz, while Richard Courant and Godfrey H. Hardy were visitors that year. He

230

A. M. TURine

[Nov. 12,

ON COMPUTABLE NUMBERS, WITH AN APPLICATION TO THE ENTSCHEIDUNGSPROBLEM

By A. M. Turrsc.

[Received 28 May, 1936.-Read 12 November, 1936.]

The "computable" numbers may be described briefly as the real numbers whose expressions as a decimal are calculable by finite means. Although the subject of this paper is ostensibly the computable numbers. it is almost equally easy to define and investigate computable functions of an integral variable or a real or computable variable, computable

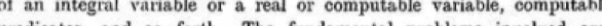
predicates, and so forth. The fundamental problems involved are, however, the same in each case, and $I$ have chosen the computable numbers for explicit treatment as involving the least cumbrous technique. I hope shortly to give an account of the relations of the computable numbers, functions, and so forth to one another. This will include a development of the theory of functions of a real variable expressed in terms of com putable numbers. According to my definition, a number is computable if its decimal can be written down by a machine.

In $\$ 9,10$ I give some arguments with the intention of showing that the computable numbers include all numbers which could naturally be regarded as computable. In particular, I show that certain large classes of numbers are computable. They include, for instance, the real parts of all algebraic numbers, the real parts of the zeros of the Bessel functions. the numbers $\pi, e$, etc. The computable numbers do not, however, include all cefinable numbers, and an example is given of a definable number which is not computable.

Although the class of computable numbers is so great, and in many rays similar to the class of real numbers, it is nevertheless enumerable. In \& 8 I examine certain arguments which would seem to prove the contrary. In gs the camine contrary. reached which are superficially similar to those of Godel †. These results

$\dagger$ Godel, "Über formal unentacheidharo Satzo dor Principia Mathornetica und ver.

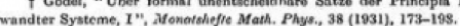

had hoped to find Gödel, but he was not there. "The mathematics department here," he wrote home on October 6, 1936, "comes fully up to expectations. There is a great number of the most distinguished mathematicians here. J. v. Neumann, Weyl, Courant, Hardy, Einstein, Lefschetz, as well as hosts of smaller fry. Unfortunatelly there are not nearly so many logic people here as last year. Church is here of course, but Gödel, Kleene, Rosser and Bernays who were here last year have left. I don't think I mind very much missing any of these except Gödel. Kleene and Rosser are, I imagine, just disciples of Church and have not much to offer that I could not get from Church. Bernays [I] think is getting rather 'vieux jeu': that is the impression I get from his writings, but if I were to meet him I might get a different impression"7.

Under Church's supervision Turing, who spent the years 1936-1938 at Princeton, wrote a Ph.D. entitled Systems of Logic Based on Ordinals ${ }^{8}$. According to Solomon Feferman, it "was the first systematic attempt to deal with the natural idea of overcoming the Gödelian incompleteness of formal systems by iterating the adjunction of statements - such as the consistency of the system - that 'ought to' have been accepted but were not derivable; in fact these kinds of iterations can be extended into the transfinite" ${ }^{\prime \prime}$.

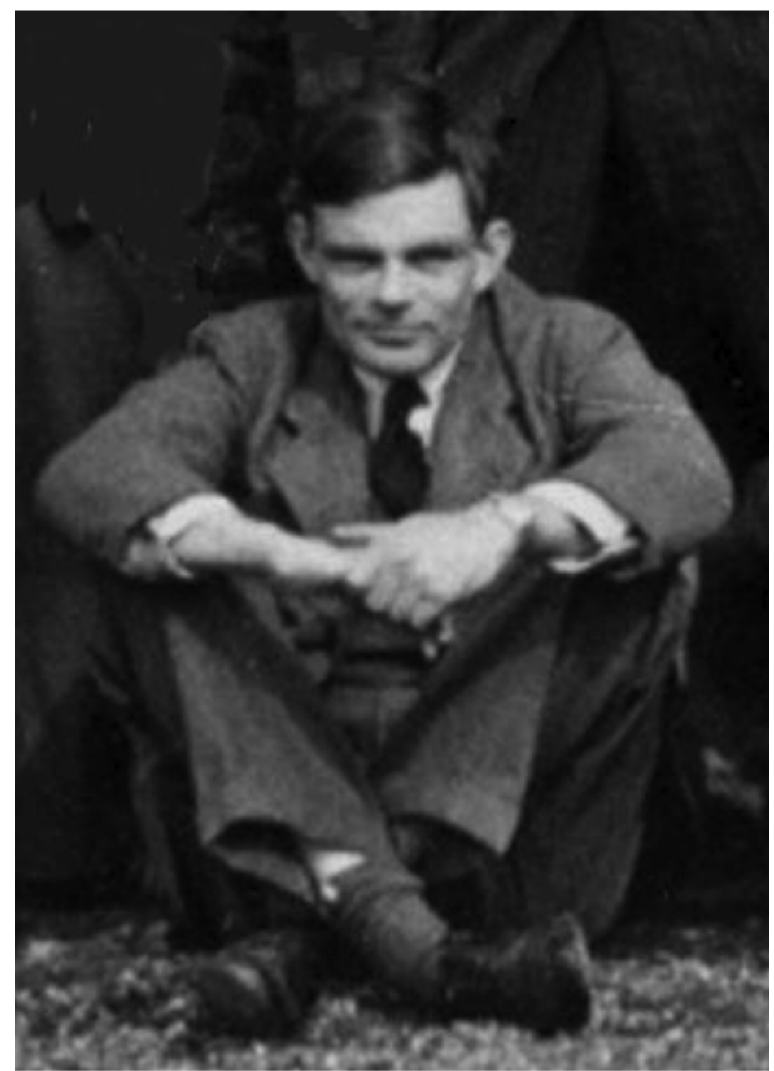




\section{TURING MACHINES AND COMPUTERS}

In his 1936 paper, Turing introduced his famous "Turing machine." Basically, a Turing Machine consists of a scanner and a limitless memory-tape that moves back and forth past the scanner. The tape is divided into squares, each of which may be blank or may bear a single symbol; for example: 1 or 0 . In other words, the Turing machine gave reality to Boole's theoretical idea of digitalization. As a matter of fact, Turing emphasized this characteristic of the new computing engines. Thus, in a lecture he delivered on February 20, 1947 at the London Mathematical Society he stated (Copeland, 2004):

\begin{abstract}
"The automatic computing engine now being designed at N.P.L. [National Physical Laboratory] is a typical large scale electronic digital computing machine [...] From the point of view of the mathematician, the property of being digital should be of greater interest that that of being electronic. That it is electronic is certainly important because these machines owe their high speed to this, and without the speed it is doubtful if financial support for their construction would be forthcoming. But this is virtually all that there is to be said on that subject. That the machine is digital however has more subtle significance. It means firstly that numbers are represented by sequences of digits which can be as long as one wishes. One can therefore work to any desired degree of accuracy [...] A second advantage of digital computing machines is that they are not restricted in their applications to any particular type of problem."
\end{abstract}

According to Copeland, who edited Turing's main papers and lectures, "On computable numbers" "is regarded as the founding publication of the modern science of computing. It contributed vital ideas to the development, in the 1940s, of the electronic storedprogram digital computer. [It] is the birthplace of the fundamental principle of the modern computer, the idea of controlling the machine's operations by means of a program of coded instructions stored in the computer's memory." (see Copeland, 2004)

As Copeland pointed out, Turing was not the only the theoretical mind to have produced an idea basic for the development of computers: he was also involved in their construction. We do not know, and cannot know, whether he would have developed such interests if the political events had been different, but the fact is that what happened shortly after he returned to England prompted him in such directions.

It was in the summer of 1938 when Turing returned to Cambridge, to his fellowship at King's College, although not for long: in September 1939, soon after the outbreak of the Great War, which in due course would be named the First World War, he moved to the headquarters of the Government Code and Cypher School at Bletchley Park ${ }^{10}$. There Turing participated in the decryption of messages sent by the German military encrypting machine called the Enigma. Turing's main contribution was the design of a machine called a "Bombe", which proved very effective in deducing the settings of Enigma on a particular day (for which the seizure beforehand of a code book from a German captured submarine by the British proved to be essential). To help the Americans to build their own Bombes, Turing spent several months in the United States: he departed on November 1942 and returned on March 1943.

Before Turing left England for America, he had become involved at Bletchley Park in another problem: how to translate the German messages sent by a machine, called Tunny, which encrypted teleprinter messages. He invented a method, known as Turingery, with which those messages could be read. Building on Turing's method, a group directed by Turing's teacher, Max Newman, in which the telephone engineer Thomas Flowers (1905-1998) played a leading role, designed more general methods of attacking Tunny that were eventually implemented in Colossus, the first electronic computer (it preceded by two years ENIAC, the Electronic Numerical Integrator And Computer designed and constructed at the University of Pennsylvania). Although it was an engineering marvel (it contained 1,500 vacuum tubes), Colossus was unlike a modern computer: to set the machine up for a new job, it was necessary to change some of the machine's wiring manually by means of switches and plugs. It became operational on February 1944. The timing of the D-day landings was based on intelligence produced by this computer.

Peter Hilton (1923-2010), another of the mathematicians who worked in Bletchley Park, recalled Turing's work there in the following terms (Hilton, 1989):

"It is a rare experience to meet an authentic genius. Those of us privileged to inhabit the world of scholarship are familiar with the intellectual stimulation furnished by talented colleagues. We can admire the ideas they share with us and are usually able to understand their source; we may even often believe that we ourselves could have created such concepts and originated such thoughts. However, the experience of sharing the intellectual life of a genius is entirely different; one realizes that one is in the presence of an intelligence, a sensibility of such profundity and originality that one is filled with wonder and excitement. 
Alan Turing was such a genius, and those, like myself, who had the astonishing and unexpected opportunity, created by the strange exigencies of the Second World War, to be able to count Turing as colleague and friend will never forget that experience, nor can we ever lose its immense benefit to us.

Turing was a mathematician, a logician, a scientist, a philosopher - in short, a thinker [...]

Much has been written in recent years of the astonishing success of 'Britain's secret weapon' [...] Others of us shared the excitement of successful achievement; some, like the mathematician Max Newman, deserved great credit for providing the organizational framework - not to be confused with its antithesis of bureaucratic structure - essential to the full exploitation of that success; but Turing stood alone in his total comprehension of the nature of the problem and in devising its solution - essentially by inventing the computer."

Also worth quoting is what Max Newman, Turing's mentor at Cambridge and colleague at Bletchley Park, said in the obituary he wrote for the Royal Society (Newman, 1955):

"In 1938 Turing returned to Cambridge; in 1939 the war broke out. For the next six years he was fully occupied with his duties for the Foreign Office. These years were happy enough, perhaps the happiest of his life, with full scope for his inventiveness, a mild routine to shape the day, and a congenial set of fellow-workers. But the loss of his scientific work of the years between the ages of 27 and 33 was a cruel one. Three remarkable papers written just before the war, on three diverse mathematical subjects, show the quality of the work that might have been produced if he had settled down to work on some big problem at that crucial time."

In any event, everything that was produced during the war convinced Turing of the possibilities and feasibility of computers. Thus, he declined an offer of a Cambridge University lectureship, accepting instead in 1945 a position at the National Physical Laboratory to form part of a group dedicated to the design, construction and use of a large automatic computing machine. He stayed there for three years, contributing to the design of the first plan of that computer, ACE. In 1948, he accepted a Readership at Manchester University, where he was appointed Assistant Director of Madam, the Manchester Automatic Digital Machine designed by F. C. Williams and T. Kilburn that apparently had at the time the largest memory storage capacity. Soon after, in June 1949 a journalist from The Times asked him in a telephone interview about the possibilities of the machine. Published on June 11, Turing was quoted to have said: ${ }^{11}$
"We have to have some experience with the machine before we know its capabilities. It may take years before we settle down to the new possibilities but I do not see why it should not enter any one of the fields normally covered by the human intellect, and eventually compete on equal terms. I do not think you can even draw the line about sonnets, though the comparison is perhaps a little bit unfair because a sonnet written by a machine will be better appreciated by another machine."

\section{ANOTHER LETTER, NOT SO FAMOUS AS EINSTEIN'S}

It is well-known that Albert Einstein wrote a letter to President Roosevelt asking him to promote nuclear research in view of the danger posed by German scientists who having discovered the fission of uranium in December 1938, might be able to produce an atomic bomb. On October 21, 1941, together with a few colleagues (W. G. Welchman, C. H. O'D. Alexander and P. S. Milner-Barry), Turing also wrote a letter in a similar vein to Winston Churchill asking him to help in a scientific and technological project. As one of my purposes in this paper is to compare Einstein and Turing, as well as to point out the special status of the former in the history of the XXth century, his preoccupations and interventions in social and political matters are invariably mentioned, I quote the opening paragraphs from that letter: ${ }^{12}$

“Dear Prime Minister,

Some weeks ago you paid us the honour of a visit, and we believed that you regard our work as important. You will have seen that, thanks largely to the energy and foresight of Commander Travis, we have been well supplied with the 'bombes' for the breaking of the German Enigma codes. We think, however, that you ought to know that this work is being held up, and in some cases is not being done at all, principally because we cannot get sufficient staff to deal with it. Our reason for writing direct is that for months we have done everything that we possible can through the normal channels, and that we despair of any early improvement without your intervention. No doubt in the long run these particular requirements will be met, but meanwhile still more precious months will have been wasted and as our needs are continually expanding we see little hope of ever being adequately staffed."

\section{TECHNOSCIENCE}

Logicians such as Boole, Russell, Whitehead, Gödel and Church were impressive mathematicians and logicians who can certainly hold their own with Turing as regards the importance of their contributions to 
the foundations of mathematics, but none of them had what Turing had: the interest in and ability to contribute to technology as well. It is not only, nor mainly, that "On computable numbers" contained the essential ideas of the computer, but rather that Turing combined a wide range of mathematical advances with far-sighted applications. This aspect of his personality and work was recognized early on; what follows is taken from an obituary published in the Manchester Guardian in June 11, 1954, under the title of "Dr. Alan Turing. An appreciation," and written by a certain M. H. A. N:

"In the death of Alan Turing, mathematics and science have lost a great original thinker. It is in connection with the big computing machines, which he helped to design and then to use, that he is best known to the general public, but it was, ironically enough, in the course of a 'logical' proof that not all mathematics can be mechanised that he was first led to give the specification of a 'universal' computing machine. To show that no machine can answer all mathematical questions, you have to say precisely what you mean by a machine.

Turing's answer to this question was theoretical in the sense that considerations of 'how fast?' and 'how large?' (then irrelevant) were ignored. But it was a real machine, with a paper tape, and he was already interested at that time in the possibility of making it. Later he threw himself with enthusiasm into the work of designing a computing machine for practical use, making use of ideas which others had had independently in the meantime.

Turing took a particular delight in problems, large or small, that enable him to combine mathematical theory with experiments he could carry out, in whole or part, with his own hands. He was ready to tackle anything which combined these two interests."

As far as I know, only John von Neumann (19031957), also an extraordinary mathematician, combined such abilities, both theoretical and applied ${ }^{13}$. So, we can say that one of the main characteristics of the XXth century, to the extent that a new term, Technoscience, was coined to express it, was that of closing the gap between science and technology, which was pioneered by two specialists in the obstensibly more abstract science of mathematics.

Since the name of von Neumann has arisen, I would like to point out, following George Dyson, that they were quite different personalities (see Dyson, 2012):

"Turing and von Neumann were as far apart, in everything except their common interest in computers, as it was possible to get. Von Neumann rarely appeared in public without a business suit; Turing was usually unkempt. 'He tended to be slovenly,' even his mother admits. Von Neumann spoke freely and with great precision; Turing's speech was hesitating, as if words could not keep up with his thoughts. Turing stayed in hostels and was a competitive long-distance runner; Von Neumann was resolutely nonathletic and stayed in first-class hotels. Von Neumann had an eye for women, while Turing preferred men.

When von Neumann spoke about computing, he never mentioned artificial intelligence. Turing spoke about little else."

\section{ARTIFICIAL INTELLIGENCE}

One of the characteristics which often goes with great innovators is that they imagine - perhaps it would be more appropriate to say, that they dream - possibilities which do not materialize soon, if ever. Thus, Albert Einstein thought of a unified theory for all the forces known at the time (electromagnetism and gravitation), which he never achieved, and which when it was recreated by others took a very different form, in the quantum realm. One of Turing "dreams" was Artificial Intelligence, a field - still not named in that manner - in which he was the first to carry out substantial research, at least in what we may call a "modern way."

As a matter of fact, that idea came to him in a rather natural way, as an extension of his previous work on computers. Such a connection can readily be discerned in the already mentioned lecture that he delivered in 1947 at the London Mathematical Society (see Copeland, 2004):

"It has been said that computing machines can only carry out the processes that they are instructed to do. This is certainly true in the sense that if they do something other than what they were instructed then they have just made some mistake. It is also true that the intention in constructing these machines in the first instance is to treat them as slaves, giving them only jobs which have been thought out in detail, jobs such that the user of the machine fully understands what in principle is going on all the time. Up till the present machines have only been used in this way. But is it necessary that they should always be used in such a manner? Let us suppose we have set up a machine with certain initial instruction tables, so constructed that these tables might on occasion, if good reason arose, modify those tables. One can imagine that after the machine had been operating for some time, the instructions would have altered out of all recognition, but nevertheless still be 
such that one would have to admit that the machine was still doing very worthwhile calculations. Possibly it might still be getting results of the type desired when the machine was first set up, but in a much more efficient manner. In such a case one would have to admit that the progress of the machine had not been foreseen when its original instructions were put in. It would be like a pupil who had learnt much from his master, but had added much more by his own work. I feel that one is obliged to regard the machine as showing intelligence."

Four years later, in another lecture, this time broadcast by BBC Radio on May 15th, 1951, he took the opportunity to insist on the possibility of Artificial Intelligence (see Copeland, 2004):

"Digital computers have often been described as mechanical brains. Most scientists probably regard this description as a mere newspaper stunt, but some do not [...] In this talk I shall [...] give most attention to the view which I hold myself, that it is not altogether unreasonable to describe digital computers as brains [...]

[The outlook of the majority of scientists] was well summed up by Lady Lovelace over a hundred years ago, speaking of Babbage's Analytical Engine. She said [...] 'The Analytical Engine has no pretensions whatever to originate anything. It can do whatever we know how to order it to perform.' This very well describes the way in which digital computers are actually used at the present time, and in which they will probably be used for many years to come $[. .$.

There is however [another] point of view, which I hold myself. I agree with Lady Lovelace's dictum as far as it goes, but I believe that its validity depends on considering how digital computers are used rather than how they could be used. In fact I believe that they could be used in such a manner that they could appropriately be described as brains."

Turing must also be credited with another idea, the so-called "Turing test," which was followed, sometimes with opposition, by those working in the field of Artificial Intelligence. He put forward this idea in an article entitled "Computing machinery and intelligence" published in Mind, a philosophical journal (see Copeland, 2004). Instead of quoting from it I will use a discussion between Turing, Newman, R.B. Braithwaite and $\mathrm{G}$. Jefferson recorded by the BBC on 10 January 1952 , and broadcast on $B B C$ radio on the 14th, and again on the 23th, of that month. On that occasion, Turing presented his idea on the following terms (Copeland, 2004):

"I don't want to give a definition of thinking, but if I had to I should probably be unable to say anything more about it than it was a sort of buzzing that went on inside my head. But I don't really see that we need to agree on a definition of a brain, or of a man, that we want to discuss, and those that we don't. To take an extreme case, we are not interested in the fact that the brain has the consistency of cold porridge [...] I would like to suggest a particular kind of test that one might apply to a machine. You avoid begging the question, and say that the machines that pass are (let's say) 'Grade A' machines. The idea is that the machine has to try and pretend to be a man, by answering questions put to it, and it will only pass if the pretence is reasonably convincing. -a considerable proportion of a jury, who should not be expert about machines, must be taken in by the pretence. They aren't allowed to see the machine itself - that would make it too easy. So the machine is kept in a far away room and the jury are allowed to ask it questions, which are transmitted through to it: it sends back a typewritten answer."

It is interesting to see what Gödel thought about Artificial Intelligence and, more specifically, about Turing's ideas in this regard. In an alternative version of some remarks Gödel intended to publish in Dialecta in 1972, brought to light in 1974 by Hao Wang and republished in Gödel's Collected Works, he criticized an argument connected with Artificial Intelligence put forward by Turing in "Computable numbers" (Gödel, 1974):

"Turing, in Proc. Lond. Math. Soc. 42 (1936), p. 250, gives an argument which is supposed to show that mental procedures cannot carry any farther than mechanical procedures. However, this argument is inconclusive, because it depends on the supposition that a finite mind is capable of only a finite number of distinguishable states. What Turing disregards completely is the fact that mind, in its use, is not static, but constantly developing. This is seen, e.g., from the infinite series of ever stronger axioms of infinity in set theory, each of which expresses a new idea or insight. A similar process takes place with regard to the primitive terms. E.g., the iterative concept of set became clear only in the past few decades. Several more primitive ideas now appear on the horizon, e.g., the self-reflexive concept of proper class. Therefore, although at each stage of the mind's development the number of its possible states is finite, there is no reason why this number should not converge to infinity in the course of its development. Now there may exist systematic methods of accelerating, specializing, and uniquely determining this development, e.g. by asking the right questions on the basis of a mechanical procedure. But it must be admitted that the precise definition of a procedure of this kind would require a substantial deepening of our understanding of the 
basic operations of the mind. Vaguely defined procedures of this kind, however, are known, e.g., the process of defining recursive well-orderings of integers representing larger and larger ordinals or the process of forming stronger and stronger axioms of infinity in set theory."

Though I cannot develop this question here, I should mention that the Turing test has not been accepted by everybody. Among its critics are figures such as John Searle, who put forward the so-called "Chinese room argument," and Paul and Patricia Smith Churchland ${ }^{14}$.

As to Turing's expectations of when Artificial Intelligence would be achieved, he was cautious (Copeland, 2004): "I believe that in about fifty years' time it will be possible to program computers, with a storage capacity of about $10^{9}$, to make them play an imitation game so well that an average interrogator will not have more than 70 per cent chance of making the right identification after five minutes of questioning. The original question, 'Can machines think?' I believe to be too meaningless to deserve discussion. Nevertheless I believe that at the end of the century the use of words and general educated thinking will have altered so much that one will be able to speak of machines thinking without expecting to be contradicted."

More than fifty years have passed and Artificial Intelligence is yet to arrive. I am not sure, however, that the kind of Al that Turing had in mind has not yet been produced, as the case of chess shows with the victory that the IBM "Deep Blue" computer achieved in May 11, 1997 in its match against world-champion Garry Kasparov.

Indeed, to anybody interested in artificial intelligence, chess is a very good playground. It is therefore not surprising that Turing made some excursions into that topic, such as the essay entitled "Chess", which appeared in a collection published in 1953 under the title Faster than Thought ${ }^{15}$

"When one is asked 'Could one make a machine play chess?', there are several possible meanings which might be given to the words. Here are a few:

i) Could one make a machine which would obey the rules of chess, i. e. one which would play random legal moves, or which could tell one whether a given move is a legal one?

ii) Could one make a machine which would solve chess problems, e.g. tell one whether, in a given position, white has a forced mate in three?

iii) Could one make a machine which would play a reasonably good game of chess, i.e. which con- fronted with an ordinary (that is, not particularly unusual) chess position, would after two or three minutes of calculation, indicate a passably good legal move?

iv) Could one make a machine play chess, and improve its play, game by game, profiting from its experience?"

\section{A PRECURSOR OF NETWORKS OF ARTIFICIAL NEURONS (CONNECTIONISM)}

Related to his interests in Artificial Intelligence, Turing also came up with what we might call "networks of artificial neurons", sometimes called connectionism, and also neural networks. He introduced a type of neural network that he called a "B-type unorganised machine," consisting of artificial neurons. Probably the best proof of his ideas in this subject was a report he prepared in 1948 entitled Intelligent Machinery, while he was working at the National Physical Laboratory. The typewritten manuscript is reproduced in the AlanTuring.net Archives, directed by Jack Copeland and Diane Proudfoot. The purpose of that work was "to investigate the question as to whether it is possible for machinery to show intelligent behavior," and it is in Section 4 ("Unorganised machines") that Turing introduced the idea of networks of artificial neurons: ${ }^{16}$

\begin{abstract}
"So far we have been considering machines which are designed for a definite purpose (though the universal machines are in a sense an exception). We might instead consider what happens when we make up a machine in a comparatively unsystematic way for some kind of standard components. We could consider some particular machine of this nature and find out what sort of things it is likely to do. Machines which are largely random in their construction in this way will be called 'unorganised machines'. This does not pretend to be an accurate term. It is conceivable that the same machine might be regarded by one man as organized and by another as unorganised.
\end{abstract}

A typical example of an unorganized machine would be as follows. The machine is made up from a rather large number $\mathrm{N}$ of similar units. Each unit has two input terminals, and has an output terminal which can be connected to the input terminals of ( 0 or more) other units."

A possibility that occurred to Turing was that the human brain is in fact closer to an unorganized machine than to an organized one; an unorganized machine which nevertheless is able to produce organized thoughts. 


\section{FROM ARTIFICIAL INTELLIGENCE TO ARTIFICIAL LIFE} (MORPHOGENESIS)

Another step in Turing's continuous intellectual development was the work he did on Morphogenesis, the science that studies the biological processes that cause an organism to develop its shape. As we can easily imagine, he used his expertise in computers to construct computer simulations to investigate the organization and patterns in living beings. Soon after the world's first manufactured general-purpose electronic digital computer, the Ferranti Mark I, was installed in the Computing Machine Laboratory of Manchester University, where Turing was working, he used it for morphogenesis studies. As he wrote in a February 1951 letter to Michael Woodger, who had worked as his assistant in 1946 at the National Physical Laboratory: ${ }^{17}$ "Our new machine is to start arriving on Monday. I am hoping as one of the first jobs to do something about 'chemical embryology.' In particular I think one can account for the appearance of Fibonacci numbers in connection with fir-cones." The outcome of such work was an article entitled "The chemical basis of morphogenesis", which Turing published in 1952 in the Philosophical Transactions of the Royal Society, and in which he presented a mathematical model of a growing embryo (see Copeland, 2004). Among the results he obtained, one was of particular importance: the demonstration that certain types of dynamic systems which are initially homogeneous undergo a progressive change which leads to the appearance of spatial heterogeneity. And, what is life but organized systems which present heterogeneities?

\section{INTERDISCIPLINARITY}

As we see, Turing's contributions to science covered a wide range, from the foundations of mathematics to cryptanalysis, computers, artificial intelligence and morphogenesis, contributions that always had deep philosophical implications ${ }^{18}$. His particular case, in the logical continuity that took him from one field to another, reminds me of Louis Pasteur, whose many and different contributions to science followed one after the other, each one motivated by the preceding one and paving the way to the next. Pasteur began by studying molecular asymmetry from a chemical and physical point of view, and then went on to fermentation because an optically active substance is involved in it; while engaged in his fermentation studies, he discovered the phenomenon now named after him, pasteurization, as well as germ theory, and demonstrated that the growth of bacteria was not due to any spontaneous generation; and from there he proceeded to immunology and vaccination.
Interdisciplinarity, the collaboration between specialists in different fields with the aim of understanding nature better, is in my opinion an emergent field which continues to grow during the XXIst century, to the extent that it constitutes one of its main characteristics ${ }^{19}$. And, in the practice of his work rather than an ideologue of interdisciplinarity, Alan Turing was both a citizen of that world and a pioneer in it.

\section{ALAN TURING'S TRAGIC FATE}

Now, let us go back to the question of the "Person of the Century," and to the two finalists who, for Time, accompanied Einstein: Roosevelt and Gandhi.

Among the arguments used by Time in favor of Roosevelt, one was based on his 1941 New Year's Day address, in which he said: "We look forward to a world founded upon four essential human freedoms: freedom of expression, freedom of worship, freedom from want, freedom from fear." And of Gandhi, we read: "In a century marked by brutality, Gandhi perfected a different method of bringing about change, one that would turn out (surprisingly) to have more lasting impact."

Unlike Gandhi's civil disobedience movement, Turing did not oppose publically those who suppressed an individual right, the freedom of sexual expression. Indeed, Turing did not fight openly those who supported the penalization of homosexuality and consequently he himself, but rather he did so in another more dramatic way: by committing suicide. After having accepted treatment with female hormones (chemical castration) as an alternative to prison, he ate an apple injected with cyanide ${ }^{20}$. Like Gandhi, who did not live to see the full realization of his dream, neither did Turing live to see the social and legal acceptance of homosexuality in his country, and while that freedom is not yet fully recognized around the world, in his own private way Turing was a victim of the denial of civil rights that existed in his time.

Summing up the merits that the Time article outlined in the case of Albert Einstein, we find:

"As the century's greatest thinker, as an immigrant who fled from oppression to freedom, as a political idealist, he best embodies what historians will regard as significant about the $20^{\text {th }}$ century. And as philosopher with faith both in science and in the beauty of God's handiwork, he personifies the legacy that has been bequeathed to the next century.

In a hundred years, as we turn to another century - nay, ten times a hundred years, when we turn to another new millennium - the name that will prove 
most enduring from our amazing era will be that of Albert Einstein: genius, political refugee, humanitarian, locksmith of the mysteries of the atom and the universe."

With the exception, if taken literally, of the reference to his supposed "faith in the beauty of God's handiwork," such a summary is an accurate expression of Einstein's achievements. However, it would also have been possible to write a moving and precise characterization of Turing's achievements, as follows:

"As a humble and most creative man, who travelled through several of the most basic sciences created by humanity, adding new ideas and perspectives to them, without distinguishing between science on one side and technology on the other, thereby revealing a new way of perceiving Nature, Turing personifies the legacy that has been bequeathed to the next century.

As a individual who fought with the best of his abilities for the freedom of his country and the world at a time when freedom was in serious danger, although that freedom was not afforded him until later, the name of Alan Turing will be remembered when the memory of his time will perhaps be but an obscure shadow."

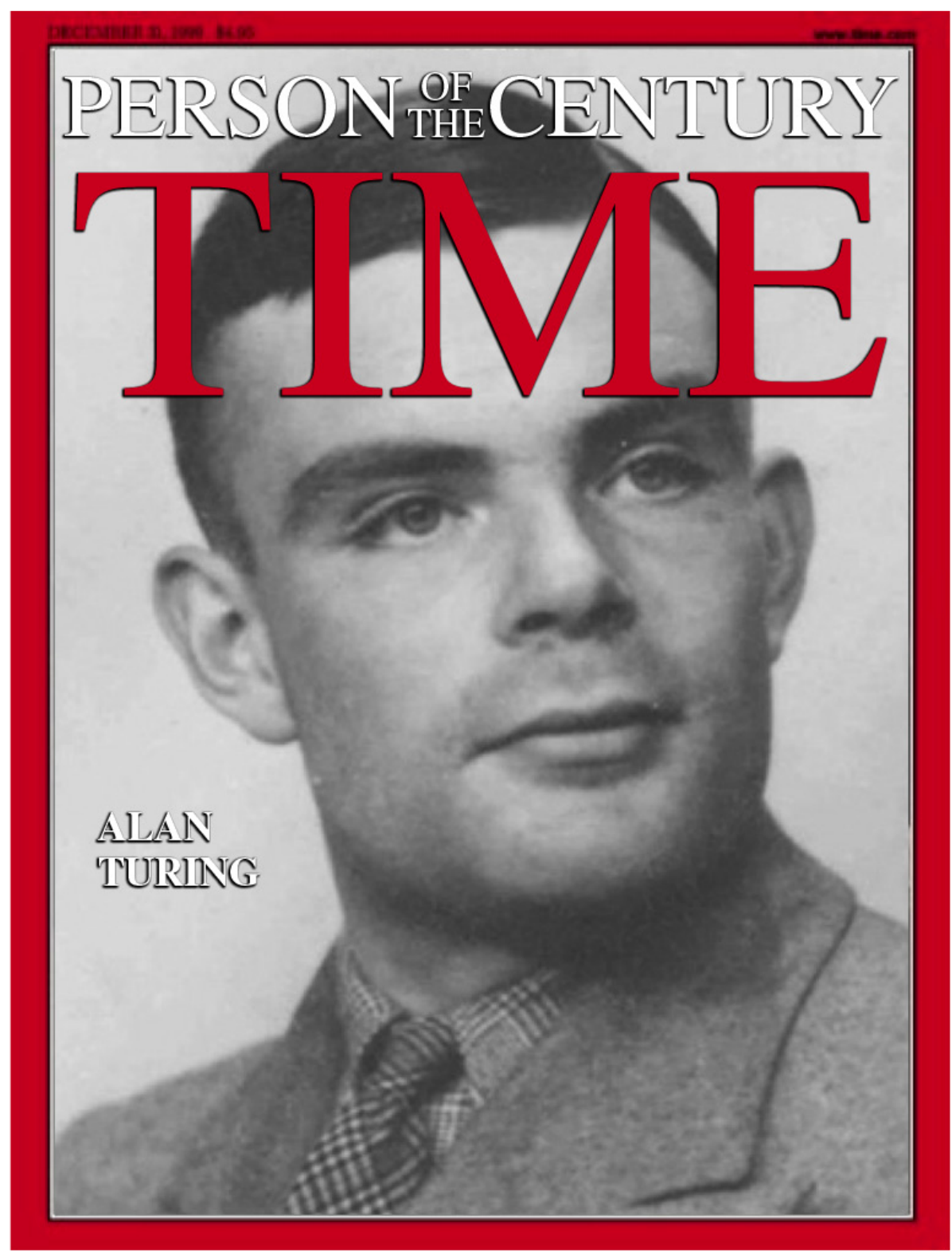


1 This article is an expanded version of the lecture I delivered at the International Symposium The Alan Turing Legacy, held at the Fundación Ramón Areces, Madrid, October 23-24, 2012. thank Prof. Manuel de León for his kind invitation and help with this paper.

2 Hilbert's lecture was of course delivered in German ("Mathematische probleme"). This is how Hilbert enunciated Problem number: "When we are engaged in investigating the foundations of a science, we must set up a system of axioms which contains an exact and complete description of the relations subsisting between the elementary ideas of that science. The axioms so set up are at the same time the definitions of those elementary ideas; and no statement within the realm of the science whose foundation we are testing is held to be correct unless it can be derived from those axioms by means of a finite number of logical steps. Upon closer consideration the question arises: Whether, in any way, certain statements of single axioms depend upon one another, and whether the axioms may not therefore contain certain parts in common, which must be isolated if one wishes to arrive at a system of axioms that shall be altogether independent of one another."

3 Turing attended Newman's lectures on logic in Cambridge. For more information about Turing's life and career, see Newman, 1955; Leavitt, 2006; Hodges, 2012; Turing, 2012.

4 My presentation of the history of this important chapter of the history of logics is too limited. More information, coming from another of the protagonists, is contained in (Kleene, 1989).
5 See Turing, 1937a and Turing, 1937b. Although received by the Proceedings of the London Mathematical Society on 28 May, 1936, and read on November 12, Turing's paper appeared in 1937 although it is sometimes referred to as if it had been published in 1936.

6 Both, these lectures and its postcriptum, were published in Davis (1965)

7 Reproduced in Copeland (2004, p. 127).

8 Turing's thesis was published with the same title in Turing (1939). The manuscript has been reprinted recently in Appel (2012).

9 Solomon Feferman, "Turing's thesis," in Alan Turing's System of Logic. The Princeton Thesis, op. cit., pp. 13-26; on p. 13.

10 For more first-hand information about Bletchley Park, see Hilton (1989).

11 Quoted in Turing (2012, p. 89)

12 Reproduced in Hilton (1989, pp. 336-337).

13 It would be interesting, though rather long, to explore the similarities, analogies and relations between Turing's and von Neumann's work. As mentioned before, Turing met von Neumann in Princeton, and the Hungarian mathematician thought sufficiently highly of Turing's talents to offer him a position as his assistant at the Institute for Advanced Study, which Turing refused, deciding to return to England. For von Neumann's opinions of Turing's 1937 work, see, for instance what he wrote about Turing's theory of computing automata in von Neumann $(1948,1995)$. Also a letter von Neumann wrote to J. C. C. McKinsey on February 18, 1948, reproduced in von Neumann (2005).
14 See Searle (1980) and also Searle (1990) and Churchland and Smith (1990). There is a recent Spanish edition of these two papers: John R. Searle, “¿Es la mente un programa informático?" and P. M. Churchland and P. Smith Churchland “¿Podría pensar una máquina?”, Investigación y Ciencia. Temas, n.ㅇ 68 ("La ciencia después de Alan Turing"), 2으 trimestre 2012, pp. 83-89, 90-96.

15 Actually, the title Turing gave to this essay in his typescript was "Digital computers applied to games."

16 Reproduced in AlanTuring.net ("The Turing Archive for the History of Computing").

17 Reproduced in AlanTuring.net ("The Turing Archive for the History of Computing").

18 I have not dealt with another field which Turing influenced: linguistics. As a mere example of such influence, I will reproduce part of the abstract from an article by Noan Chomsky, the great linguist: "A grammar can be regarded as a device that enumerates the sentences of a language. We study a sequence of restrictions that limit grammars first to Turing machines, then to two types of systems from which a phrase structure description of the generated language can be drawn and finally state Markov sources (finite automata)." See Chomsky (1959).

19 I have developed this thesis in Sánchez Ron (2011). For a general evaluation of the interdisciplinary studies, see Frodeman (2010).

20 There are people who think that Turing did not commit suicide, but that he ate an apple which had been contaminated accidentally. 
Appel, A.W. (Ed.) (2012). Alan Turing's System of Logic. The Princeton Thesis. Princeton: Princeton University Press.

Chomsky, N. (1959). "On certain formal properties of grammars". Information and Control, 2, pp. 137-167.

Church, A. (1936a). "An unsolvable problem of elementary number theory". American Journal of Mathematics, 58, pp. 345-363.

Church, A. (1936b). "A note on the Entscheidungsproblem". Journal of Symbolic Logic, 1, pp. 40-41.

Church, A. (1936c). "A note on the Entscheidungsproblem, Correction". Journal of Symbolic Logic, 1, pp. 101-102.

Churchland, P. M and Smith Churchland, P. (1990). "Could a machine think?". Scientific American, 262 (1), pp. 26-31 and pp. 32-37.

Copeland, J. (ed.) (2004). The Essential Turing. Oxford: Clarendon Press, p. 127.

Davis, M. (ed.) (1965). The undecidable: Basic Papers on Undecidable Propositions, Unsolvable Problems and Computable Functions. Hewlett, N. Y.: Raven Press, pp. 39-74.

Dyson, G. (2012). Turing's Cathedral. New York: Pantheon Books, p. 259.

Frodeman, R. (ed.) (2010). The Oxford Handbook of Interdisciplinarity. Oxford: Oxford University Press.

Gödel, K. (1931). “Über formal unentscheidbare Sätze der Principia Mathematica und verwandter Systeme I". Monantshefter für Mathematik und Physik, 38, pp. 173-198.

Gödel, K. (2003). Collected Works, vol. V (Correspondence H-Z), S. Feferman, J. W. Dawson, jr., W. Goldfarb, Ch. Parsons and W. Sieg, eds.; Clarendon Press, Oxford, p. 147.

Gödel, K. (1958). “Über eine bisher noch nicht benützte Erweiterung des finiten Standpunktes" ("On a hitherto unutilized extension of the finitary standpoint"). Dialectica 12, pp. 280287; pp. 245, 275.

Gödel, K. (1934). "Postcriptum" to On undecidable propositions of formal mathematical systems (mimeographed lecture notes delivered in 1934). Published in Martin Davis (ed.), The undecidable: Basic Papers on Undecidable Propositions, Unsolvable Problems and Computable Functions. Hewlett, N. Y.: Raven Press, pp. 39-74.

Gödel, K. (1974). "Some remarks on the undecidability results". In Hao Wang, From Mathematics to Philosophy. New York: Routledge and Kegan Paul, pp. 325-326.

Hilbert, D. (1902). "Problèmes futures des Mathématiques". In Compte Rendu du Deuxième Congrès International des Mathématiciens tenu a Paris du 6 au 12 Aout 1900, Gauthier-Villars, Paris, pp. 58-114.

Hilbert, D. (1929, 1930). "Probleme der Grundlegung der Mathematik". Atti del Congresso Internazionale dei Matematici. Bologna 3-10 Settembre 1928, tome I. Nicola Zanichelli, Bologna 192), pp. 135141; also published in Mathematische Annalen 102, 1-9 (1930); pp. 3-9.

Hilton, P. (1989). "Reminiscences of Bletchley Park, 1942-1945" In A Century of Mathematics in America, Part I, pp. 291-301.

Hodges, A. (2012). Alan Turing: The Enigma. Simon and Schuster, New York 1983; new edition: Random House, London.

Isaacson, W. (1999). "Who mattered and why", Time, December 31, 1999.

Kleene, S.C. (1989). "The role of logical investigations in Mathematics since 1930". In A Century of Mathematics in America, Part I, Peter Duren, ed.; American Mathematical Society, Providence, Rhode Island, pp. 85-94.

Leavitt, D. (2006). The Man Who Knew too Much: Alan Turing and the Invention of the Computer. Norton, New York.
Newman, M. H. A. (1955). "Alan Mathison Turing, 1912-1954". Biographical Memoirs of Fellows of the Royal Society 1, pp. 253-263.

Sánchez Ron, J. M. (2011). La Nueva Ilustración Ciencia, tecnología y humanidades en un mundo interdisciplinar. Oviedo: Ediciones Nobel.

Searle, J. R. (1980). “Minds, brain and programs". Behavioral and Brain Sciences, 3, pp. 417-457.

Searle, J. R. (1990). "Is the brain's mind a computer program?". Scientific American, 262 (1), pp. 26-31.

Turing, A. (1937a). “On computable numbers, with an application to the Entscheidungsproblem". Proceedings of the London Mathematical Society, 42, pp. 230-265.

Turing, A. (1937b). “On computable numbers, with an application to the Entscheidungsproblem. A correction". Proceedings of the London Mathematical Society, 43, pp. 544-546.

Turing, A. (1939). "Systems of Logic Based on Ordinals". Proceedings of the London Mathematical Society 2, pp. 161-228.

Turing, S. (2012). Alan M. Turing. W. Heffer \& Sons, 1959; new edition: Cambridge University Press, Cambridge.

von Neumann, J. (1948, 1995). "The general and logical theory of automata". In Cerebral Mechanisms in Behavior - The Hixon symposium September 1948, L. A. Jeffress, ed. (California Institute of Technology), reprinted in The Neumann Compendium, F. Bródy and T. Vámos, eds. (World Scientific, Singapore 1995), pp. 526-556; see pp. 551-553.

von Neumann, J. (2005). Selected Letters, Miklós Rédei, ed. American Mathematical Society/London Mathematical Society, pp. 178-179. 